\title{
OBMEP NA ESCOLA: AS LIÇÕES E EXPERIÊNCIAS DE UMA FORMAÇÃO EM MATEMÁTICA
}

\author{
OBMEP IN SCHOOL: THE LESSONS AND EXPERIENCES OF A TRAINING IN MATHEMATICS
}

\author{
Dermeval Santos Cerqueira ${ }^{1}$
}

\section{RESUMO}

Durante os últimos três anos atuei como formador de professores da rede pública estadual de São Paulo que se inscreveram para atuarem como preparadores de alunos que iriam participar das olimpíadas brasileira de Matemática das escolas públicas - OBMEP. O projeto tinha como um dos objetivos contribuir para a formação de professores em Matemática estimulando estudos mais aprofundados e a adoção de novas práticas didáticas em suas salas de aula. Atuar como formador desses professores foi muito inspirador e reverbera um cenário alentador para a melhoria do Ensino/Aprendizagem de Matemática no Ensino Fundamental Anos Finais e/ou Médio. Embora o projeto OBMEP NA ESCOLA era para alunos que realizariam as provas da OBMEP, os professores perceberam que a formação estava impactando de maneira favorável a aprendizagem de seus alunos regulares do Ensino Fundamental e/ou Médio. Os relatos dos professores e a postura de como eles se envolviam nas atividades durante a realização dos encontros de formação demonstravam que era sim, possível acreditar em formas mais dinâmicas e desafiadoras de lecionar Matemática na sala de aula. Afirmavam que, quando iniciaram a formação no projeto, as incertezas de alcançarem os resultados por meio de avaliações oficiais externas, os desconfortos em ter que inovar em suas metodologias de ensino, exigindo de cada um dos partícipes análises e reflexões sobre suas práticas educativas e, ainda, a necessidade de se apropriarem das novas tendências em ensino da Matemática veiculadas pela Educação Matemática, era desafiador e assustador. Sentimentos que se transformaram em autoconfiança e aceitação de metamorfosear. PALAVRAS-CHAVE: Metodologias de ensino. Formação de Professores. Motivar alunos.

\section{ABSTRACT}

During the last three years I worked as a trainer of teachers from public São Paulo State who signed up to act as substrate preparation of students who would participate in the Brazilian Mathematical Olympiad public schools-BMOPS. The project had as one of the objectives to contribute to the formation of teachers in Mathematics stimulating further studies and the adoption of new didactic practices in their classrooms. Acting as a trainer for these teachers was very inspiring and reverberates an encouraging scenario for the improvement of Mathematics Teaching / Learning in Final and / or Middle School. Although the BMOPS IN SCHOOL project was for students who would take the BMOPS tests, teachers realized that the training was positively impacting the learning of their regular Elementary and / or Middle School students. The teachers' reports and the posture of how they got involved in the activities during the training meetings demonstrated that yes, it was possible to believe in more dynamic and challenging ways of teaching Mathematics in the classroom. They stated that when they started training in the project, the uncertainties of achieving the results through official external evaluations, the discomforts of having to innovate in their teaching methodologies,

\footnotetext{
${ }^{1}$ Doutor em Educação Matemática pela Pontifícia Universidade Católica de São Paulo (2012) - PUC-SP, Mestre em Educação Matemática - PUC-SP (2003), Licenciado em Matemática pela mesma universidade (1998) e Licenciado em Ciência pela Universidade de Guarulhos (1994). Professor de Tempo Integral de Matemática do Centro Universitário das Faculdades Metropolitanas Unidas - FMU. Diretor de Educação do Instituto Nacional de Pesquisas Monográficas - INPEM Experiência em formação de professores de Matemática do Ensino Fundamental Anos Iniciais e Finais e de Ensino Médio nas modalidades presencial e vídeo conferência. Coautor do Livro didático de Ensino Médio "O universo da Matemática" Ed. Escala Educacional. Coautor do livro Alfabetização e letramento: prática reflexiva no processo educativo. São Paulo: Humanitas, 2014. Organizador e coautor: ALENCAR, Edvonete Souza de, CERQUEIRA, Dermeval Santos. Educação Matemática: Reflexões para aprendizagem, São Paulo. Dialógica Ed., 2016. Autor do livro: Educação Matemática: avaliar para satisfazer, São Paulo: Dialógica Ed., 2016 E-mail: dscerqueirasp@yahoo.com.br
} 
requiring each participant to analyze and reflect on their educational practices and, still, the need to appropriate the new trends in Mathematics teaching conveyed by Mathematics Education was challenging and frightening. Feelings that have turned into self-confidence and acceptance of metamorphosis.

KEYWORDS: Teaching methodologies. Teacher training. Motivate students.

\section{INTRODUÇÃO}

O presente artigo é um relato de experiência em que o autor vivenciou um trabalho com professores que lecionam na rede pública estadual de São Paulo e que desenvolveram atividades inovadoras com grupos de alunos que gostariam de participar das olimpíadas de Matemática.

Entendemos que um relato de experiência ${ }^{2}$ é um texto que descreve detalhadamente uma experiência e que esse, possa contribuir de forma relevante para, nesse caso, o ensino/aprendizagem da Matemática. O relato de experiência aventa as motivações ou metodologias para as ações tomadas na situação e as considerações/impressões que a vivência trouxe àquele (a) que a viveu. O relato é feito de modo contextualizado, com objetividade e aporte teórico. Em outras palavras, não é uma narração emotiva e subjetiva, nem uma mera divagação pessoal e aleatória.

Em julho de 2016 fui convidado, pela coordenação do Projeto OBMEP na Escola CRIC-SP 05, sediada em no município de São Bernardo do Campo, São Paulo, para trabalhar como coordenador e formador de professores da rede pública estadual de São Paulo que se inscreveram para atuarem como preparadores de alunos que iriam participar das olimpíadas brasileira de Matemática das escolas públicas - OBMEP.

De acordo com Carneiro, Lima e Silva (2016) Projeto Olimpíada Brasileira de Matemática das Escolas Públicas (OBMEP) é uma iniciativa do o Ministério da Ciência e Tecnologia (MCT) e do MEC, conta com apoio da Casa Civil, Secretaria de Comunicação de Governo e Gestão Estratégica e Secretaria de Coordenação Política e Assuntos Institucionais.

A Olimpíada Brasileira de Matemática das Escolas Públicas - OBMEP é um projeto nacional dirigido ${ }^{2 h}$ http://www.escritaacademica.com/topicos/generosacademicos/o-relato-de-experiencia/ às escolas públicas e privadas brasileiras, realizado pelo Instituto Nacional de Matemática Pura e Aplicada - IMPA, com o apoio da Sociedade Brasileira de Matemática - SBM, e promovida com recursos do Ministério da Educação e do Ministério da Ciência, Tecnologia, Inovações e Comunicações - MCTIC. ${ }^{3}$

Em 2018 o projeto passou a contar com o patrocínio do Itaú Social.

Concordo com Carneiro, Lima e Silva (2016, p. 01) quando afirmam que "[...] a Olimpíada é uma competição nacional de Matemática, seguida de programas de aperfeiçoamento para alunos premiados. É direcionada aos estudantes das escolas públicas do Ensino Fundamental ( $6^{\circ}$ ao $9^{\circ}$ ano) e do Ensino Médio".

Para atuar, como coordenador e formador, eu me apropriei da intencionalidade do projeto que tinha como um dos objetivos contribuir para a formação de professores em Matemática estimulando estudos mais aprofundados e a adoção de novas práticas didáticas em suas salas de aula.

\section{REFLETINDO SOBRE A IMPORTÂNCIA DO PAPEL DOS PROFESSORES DE MATEMÁTICA}

Para Cerqueira (2003, p. 46 apud, Gonzáles, 1999), o professor de Matemática hoje deve ser um profissional com grande competência para formular questões que estimulem a reflexão de seus alunos, que possua sensibilidade para apreciar a originalidade e a diversidade na elaboração de hipóteses e de proposições de solução aos problemas.

Cerqueira (2003, p. 46 apud, Gonzáles, 1999), entende que o professor deve ser criativo para criar ambientes e situações de aprendizagem matematicamente ricos. Também terá que possuir uma ampla capacidade para dar resposta ao imprevisto e dese-

${ }^{3}$ Disponível em http://www.obmep.org.br/apresentacao.htm 
nhar modelos que se adaptem às incertas e mutantes condições de aprendizagem que ocorrem nas aulas de Matemática.

As aulas seriam propostas em horários diferentes dos que os alunos estudavam regularmente, por exemplo, se os alunos que participariam do projeto estudassem no período da manhã eles estudariam na parte da tarde um total de 04 horas semanais com realizações de estudos, tarefas extraclasses com material impresso e online e, ainda, realizariam avaliações periodicamente.

Nós, membros da coordenação, sabíamos que era fundamental desenvolvermos um trabalho de formação que impactasse de maneira motivadora para que os professores partícipes do projeto pudessem atrair alunos para participarem do projeto OBMEP na escola.

Nesse sentido, pactuamos com González (1999) que identifica como principais papéis desse profissional:

- propiciar situações ou estratégias para que seus alunos tenham oportunidade de comunicar ideias matemáticas;

- criar e desenvolver tarefas e desafios que estimulem os estudantes a coletar, organizar e analisar informações, resolver problemas e construir argumentações lógicas;

- estimular seus alunos para que busquem alcançar um conhecimento e uma compreensão da Matemática que seja consideravelmente superior aos níveis mínimos da alfabetização numérica;

- vincular a Matemática com outras áreas do conhecimento humano, especialmente as artísticas, de modo que seus alunos desenvolvam uma sensibilidade tal que lhes permita apreciar e desfrutar o poder e a beleza da Matemática;

- relacionar a Matemática com o entorno a fim de ajudar seus alunos na tarefa de compreender como a Matemática permeia nossa vida e como os diferentes ramos da Matemática estão interconectados;

- estimular seus alunos para o uso, natural e rotineiro, da tecnologia nos processos de ensinar, aprender e fazer matemática.

Com tais preocupações, amplamente partilhadas pela coordenação do projeto consensuou-se que essa formação de professores de Matemática não poderia ter como objetivo principal o mero acúmulo de informações e/ou resolver as atividades que seriam propostas para os alunos. Era imprescindível que os professores se apropriassem das novas metodologias de ensino e aprendizagem da Matemática veiculadas pela educação Matemática, tais como, contextualização, resolução de problemas, a utilização de jogos, Modelagem Matemática, Etnomatemática, etc.

Acreditamos que, dessa forma, atenderíamos as expectativas explicitadas no sítio da OBMEP de que "Professores de todo o país serão orientados no desenvolvimento de conteúdos programáticos, seguindo a prática didática de resolução de problemas, no trabalho com grupos de alunos selecionados em suas escolas ou em escolas vizinhas".

\section{OS ATORES DESSA FORMAÇÃO E A REFLEXÃO SOBRE FORMAÇÃO DE PROFESSORES}

Os professores que participaram do projeto OBMEP na Escola de 2016 a 2018, para serem aceitos no projeto, inicialmente fizeram uma avaliação escrita e após serem aprovados foram contratados para atuarem no projeto.

A renovação, anualmente, era por meio de avaliação dos coordenadores do projeto. Observávamos se os professores eram atuantes em suas escolas, motivadores com seus alunos e assíduos nos sete encontros de formações presenciais.

A maioria dos 19 professores participantes tinha mais de cinco anos de experiência na Educação Pública. Dois desses professores atuavam na Diretoria de Ensino da rede pública em apoio pedagógico, sendo um na cidade de São Paulo e outro em Registro.

Dois professores haviam concluído mestrado em ensino e os demais possuíam especialização lato sensu.

Os professores atuavam nas cidades de São Paulo, Diadema, São Bernardo do Campo, Poá, Itaquaquecetuba, Santos, Suzano, Itanhaém, Registro e em Itapecerica da Serra.

Quando iniciamos nossos trabalhos com esses professores era notória a vontade que eles tinham de fazer a diferença em sala de aula. Nos encontros que realizávamos mensalmente eles faziam relatos, verbalmente, de como haviam trabalhado com seus 
alunos destacando qual (ais) metodologia(s) havia(m) utilizada(s) para envolver seus alunos.

Um problema que foi identificado, nas falas dos professores, era a dificuldade que os alunos tinham em registrar os procedimentos adotados para a resolução das atividades propostas.

Muitos alunos eram capazes de chegar a solução correta das situações-problema, contudo, não sabiam descrever as estratégias utilizadas para resolução. Apenas diziam: "fiz de cabeça".

Nesse sentido, entendíamos que eram necessárias algumas intervenções para ajudar os alunos a superarem esse tipo de dificuldade. Era primordial que as atividades matemáticas propostas motivassem os alunos a quererem envolver-se, individual e/ou coletivamente, para a busca da solução.

O importante era propor atividades numa perspectiva construtivista e problematizadora das ideias matemáticas, privilegiando os processos e não apenas os conhecimentos matemáticos formais (CERQUEIRA, 2003).

Privilegiar a argumentação por parte dos alunos para explicarem as escolhas dos procedimentos para a resolução poderia tornar-se uma rica experiência e vislumbraríamos diferentes estratégias pessoais dos alunos.

Mas, como promover situações-problema que levassem os alunos a quererem aprender e compreender os conceitos matemáticos envolvidos?

Essa, possivelmente era a questão norteadora de nossos trabalhos. Ainda, como mostrar para os professores que seria possível envolver os alunos nas aulas de Matemática?

Muitas questões perpassavam em nossas análises e reflexões e considerávamos que era essencial apresentar aos professores as novas tendências veiculadas pela Educação Matemática, pois, desde o início de nossos trabalhos era visível que os professores demonstravam vontade de incorporarem novas práticas metodológicas em seus planejamentos acadêmicos.

Cerqueira (2003, p. 117), ressalta que é fundamental de nossa parte, uma preocupação constante no sentido de levar em conta a formação anterior desses professores (respeitando suas angústias, atendendo suas demandas sobre os conteúdos) e a consciência de que não daríamos conta de resolver todos os pro- blemas dessa formação, na medida em que o "desenvolvimento profissional é uma aprendizagem contínua, interativa, acumulativa, que combina uma variedade de formatos de aprendizagem".

É nesse aspecto que tomamos a decisão de participar do Projeto OBMEP na Escola, pois, congraçamos que, a formação dos professores atende ao princípio que Garcia (1999, p.27) defende que é o de conceber a Formação de Professores como contínuo (Marcelo, 1989). A formação de professores é um processo que, ainda que constituído por fases claramente diferenciadas pelo seu conteúdo curricular, deverá manter alguns princípios éticos, didáticos e pedagógicos comuns independentemente do nível de formação de professores a que nós estejamos a referir.

$\mathrm{Na}$ proposta de formação desses professores entediamos como primordial a interação entre os pares que os participantes pudessem se expressar oralmente e/ou pela escrita e, também, pela "emoção". No decorrer do evento iam se sentindo mais seguros de si com relação às propostas do curso e referente às atividades que eles deveriam trabalhar em sala de aula (CERQUEIRA, 2003, p. 121).

Para Cerqueira (2003, p. 120), é fundamental o "ouvir-falar". No desenvolvimento deste projeto de formação de professores transparecia nitidamente, por meio de conversas nos encontros presenciais. Almeida (2003, p.79) afirma que "quando alguém é ouvido (e compreendido), isso traz uma mudança na percepção de si mesmo, por sentir-se valorizado e aceito. E, por sentir-se valorizado e aceito, pode apresentar-se ao outro sem medo, sem constrangimentos. Por isso, a relação empática está intimamente ligada à construção da identidade, pois "a identidade é percebida quando o próprio eu é apresentado a outro"(SCHEIBE, 1984, p.10)".

Uma vez apresentados os atores envolvidos na formação e as propostas que precisaríamos desenvolver juntamente com os professores, no próximo item, narraremos sobre as metodologias e dinâmicas que desenvolvemos com os professores ao longo das formações.

\section{ARTICULANDO INOVAÇÕES METODOLÓGICAS NO ENSINO/APRENDIZAGEM DE MATEMÁTICA}

Nos sete encontros realizados em 2017 analisamos e refletimos sobre artigos que discorriam sobre: 1 . 
Resolução de Problemas e contextualização; 2. Modelagem Matemática; 3. O papel do erro no processo de ensino/aprendizagem; 4. Jogos matemáticos; 5 . Etnomatemática.

No primeiro encontro de 2018 pedimos aos professores que formassem grupos para que pudessem escolher e apresentar um dos temas discutidos em 2017 nos próximos encontros, trazendo propostas de atividades e metodologias ativas que pudessem contribuir no processo educativo. Dessa forma, cinco grupos foram constituídos.

Elegemos três temas para apresentar nesse artigo - Resolução de Problemas, Jogo de dardo no ensino de Matemática e Modelagem Matemática.

Nossa intenção é que, por meio desses três relatos de vivencias que os três grupos proporcionaram, possamos contagiar os leitores à busca de inovações e implementação de atividades diferenciadas que possibilitem aos alunos uma experiência fascinante para aprender Matemática. Ainda, poder-se-á que o leitor venha ratificar suas ações pedagógicas em sala de aula.

A seguir, descreveremos como os grupos oportunizaram vivencias para os demais participantes da formação presencial da OBMEP e ao final de cada apresentação será explicitada as referências utilizadas por eles.

\section{Resolução de Problemas}

O Grupo 1, composto por quatro professores iniciou a sequência de apresentações com o tema Resolução de Problemas. A seguir apresentamos o texto que foi debatido sobre o tema.

\section{O FOCO NA RESOLUÇÃO DE PROBLEMAS}

Cerqueira (2012, p.55) afirma que os problemas ocuparam lugar central para a Matemática desde a Antiguidade, visto que há registros de problemas na antiga história egípcia, chinesa e grega, mas foi recentemente que esse tema tomou uma maior importância no processo ensino-aprendizagem da matemática.

Cerqueira (2012, p. 55, apud Onuchic,1999) descreve um cenário escolar para o ensino da Matemática no início do século $X X$ totalmente voltado para a repetição. A ênfase estava na memorização. Para autora, o aluno recebia a informação, escrevia, memorizava e repetia. Repetia e treinava em casa os exercícios realizados na sala de aula. O conhecimento do aluno era mensurado por meio da aplicação de testes em que ele deveria repetir, mesmo sem compreensão, por meio de tudo que o professor havia feito nas aulas.

Cerqueira (2012, p. 55) ressalta que era necessário que a aprendizagem do conhecimento matemático se efetivasse de maneira significativa para os estudantes e não apenas como uma técnica sem compreensão. Portanto, era preciso mudanças na forma de ensinar Matemática. Diversos pesquisadores nacional e internacionalmente se propuseram a refletir sobre essa mudança e trouxeram suas contribuições com foco na resolução de problemas no ensino da Matemática.

Dessa forma, para Cerqueira (2012, p. 55), no fim da década de 70 , a resolução de problemas começou a se destacar no mundo inteiro com um movimento a seu favor. Em 1980, foi editada nos Estados Unidos "Uma Agenda para a Ação Recomendações para a Matemática Escolar de 1980" (NCTM, 1980), apresentou opções didáticas que passaram a ser incorporados pelos currículos em diversos países, uma delas centrava na resolução de problemas.

Esse documento tem como objetivo, segundo Cerqueira (2012, p. 55), propor melhorias no ensino -aprendizagem da matemática. A sua primeira recomendação é que a resolução de problemas deve ser o foco principal da matemática escolar, sugerindo aos educadores matemáticos dirigirem seus esforços para que seus alunos desenvolvam a habilidade em resolvê -los, com isso destaca:

O desenvolvimento da capacidade de resolução de problemas deve orientar os esforços dos educadores matemáticos por meio da próxima década. Desempenho na resolução de problemas vai medir a eficácia de nossa posse pessoal e nacional de competência matemática (NCTM, 1980).

Cerqueira (2012, p. 56, apud ONUCHIC,1999) afirma que o documento orienta que os currículos devem ser concebidos com essa recomendação, apresentando algumas competências a serem desenvolvidas:

O currículo de matemática deve ser organizado em torno de resolução de problemas. [...] Os programas de Matemática devem proporcionar 
aos estudantes experiência na aplicação da matemática, na seleção e combinar estratégias para a situação na mão. Os alunos devem aprender a: formular perguntas-chave; analisar e conceituar problemas; definir o problema e seu objetivo; descobrir padrões e semelhanças; buscar dados adequados, experimentando-nos; transferir as habilidades e estratégias a novas situações; basear-se no conhecimento para aplicar a matemática (NCTM, 1980).

Cerqueira, (2012, p. 56, apud ONUCHIC e ALLEVATO 2011), afirmam que a Resolução de Problemas, como uma metodologia de ensino, se torna o lema das pesquisas e estudos em Resolução de Problemas para os anos 1990. Essa nova visão de ensino -aprendizagem de Matemática se apoia especialmente nos estudos desenvolvidos pelo NCTM, que culminaram com a publicação dos Standards 2000 , oficialmente chamados Principles and Standards in School Mathematics (NCTM, 2000).

As autoras, de acordo com Cerqueira (2012, p. 56) assinalam que nesse documento são assumidos os seguintes Princípios: Equidade, Currículo, Ensino, Aprendizagem, Avaliação e Tecnologia. Como padrões de Conteúdo, que respondem à questão "O quê (ensinar)?", apresentam Número e Operações, Álgebra, Geometria, Medida e Análise de Dados e Probabilidade. Para os Padrões de Procedimento, que respondem à questão "Como (ensinar)?", são apontados Resolução de Problemas, Raciocínio e Prova, Comunicação, Conexões e Representação.

Esse conjunto de orientações, de acordo com Cerqueira (2012, p. 56) permeia a possibilidade de o aluno aprender matemática de uma forma mais plausível, ou seja, ele tem a possibilidade de compreender o conteúdo proposto de uma forma significativa, entendendo onde esse conhecimento pode ou poderá ser utilizado na sociedade contemporânea. O recurso da resolução de problemas é algo que deve estar prioritariamente no discurso e na prática do professor de Matemática a cada planejamento diário de aula.

Cerqueira (2012, p. 57) acredita ter encontrado respaldo para o que afirmamos no parágrafo anterior em Lopes e Mansuti (1994) quando declaram que:
[...] o aluno tanto aprende matemática resolvendo problemas como aprende matemática para resolver problemas". Além disso, a prática de ensino nas escolas mostra que, embora existam algumas experiências que dedicam atenção às estratégias utilizadas pelos alunos durante a resolução de problemas, essas são utilizadas, em sua maioria, "[...] com a finalidade de verificar a aprendizagem e a aplicação de conceitos, algoritmos, propriedades e outros fatos da matemática (p. 35).

Cerqueira (2012, p. 57) concorda com Onuchic e Allevato,(2011) que entendem que esse movimento de reforma na Educação Matemática, vigente até hoje, aponta para a Resolução de Problemas como primeiro padrão de procedimento para o trabalho com os padrões de conteúdo, sendo que o ensino de Matemática através da resolução de problemas é nele fortemente recomendado.

Após a leitura o grupo fomentou debates sobre como alinhar o discurso teórico sobre resolução de problemas com as atividades propostas no material da OBMEP sugerindo que os professores se reunissem em grupos por níveis ${ }^{4}$ da OBMEP $(\mathrm{N} 1, \mathrm{~N} 2, \mathrm{~N} 3)$ que atuavam e elaborassem o planejamento para o próximo encontro. Cada um dos três grupos teve cerca de 30 minutos para apresentação de suas propostas e todos contribuíam com sugestões.

Os professores que lecionam para o nível 1 , apresentaram para os demais participes três atividades para resolverem. Estipularam um tempo de 30 minutos para que os demais resolvessem as três atividades. Quando iniciaram as discussões sobre quais procedimentos utilizados para a resolução, verificaram se validaram e de que forma validaram os resultados etc., os professores do N1, considerando que a primeira era muito fácil, apresentou a solução para os demais questionando se acertaram ou não.

Imediatamente, intervimos solicitando a esses professores que oportunizasse um momento para discutir como os demais professores desenvolveram a primeira atividade.

${ }^{4}$ Nível 1 - aluno s do $6^{\circ}$ ou $7^{\circ}$ ano do Ensino Fundamental. Nível 2 - alunos do $8^{\circ}$ ou $9^{\circ}$ ano do Ensino Fundamental. Nível 3 - alunos do Ensino Médio. 
Para surpresa de todos, das três atividades, a primeira foi a que mais demandou estratégias diferenciadas, sugestões de quais competências poderiam ser exploradas, além das que estavam apontadas na atividade.

Ressaltamos que não podemos subestimar as propostas acreditando que simplesmente a situação -problema é de fácil compreensão. Ela poderá ser uma riqueza dependendo da forma que conduzimos.

Outro grupo (N2) trabalhou o significado de $\mathrm{m}^{2}$. Uma das atividades projetava estimar o número de pessoas concentradas numa determinada praça, conhecendo suas dimensões. O grupo questionou como isso seria possível sem contar as pessoas uma a uma. Abriu-se discussões que esse fato ocorre costumeiramente em casos de comemorações de títulos futebolísticos de times ou seleções de países, bem como de manifestações de reivindicações em locais públicos.

Após as discussões uma professora pegou em sua bolsa um pequeno rolo de barbante e utilizando quatro carteiras e uma régua de $30 \mathrm{~cm}$, demarcou o espaço de um quadrado de lado medindo $1 \mathrm{~m}$. Em seguida, ela entrou nesse espaço para avaliar quantas pessoas com o mesmo porte físico dela caberiam dentro daquele espaço limitado pelo cordão. Ela percebeu que se fossem pessoas mais magras caberiam mais, casos as pessoas tivessem o porte físico maior que o dela, caberia menos pessoas.

Esse tipo de experiência parece tão simples, no entanto, a professora que já tem uma vivencia como adulta e como educadora, ao nosso ver, não tinha vivenciado e nem percebido o quanto era significativo esse tipo de oportunidade para aprender. Outros professores envolveram-se na atividade entrando no espaço limitado e calculando quantas caberiam no quadrado de $1 \mathrm{~m}^{2}$. Foi simplesmente fantástica essa experiência.

A metodologia ativa que foi utilizada nessa apresentação é a denominada "sala de aula invertida". A sala de aula invertida é um formato que vem ganhando força nos últimos tempos, pois coloca o estudante numa posição ativa frente a sua própria aprendizagem. O professor deixa de ser o detentor de todo o conhecimento para ser aquele que orienta e guia o estudante pelo processo de aprendizagem. O estudante deve se preparar para a aula estudando em casa o conteúdo indicado pelo docente,

Para que a sala de aula invertida aconteça, é preciso que o docente organize as atividades que serão desenvolvidas em casa de modo a preparar o estudante a participar da aula já com o conteúdo assimilado, aproveitando o tempo na Escola / Universidade para tirar dúvidas e trabalhar em grupo. O professor precisa preparar uma trilha de aprendizagem motivadora que o estudante deve realizar em casa e desenvolver em sala exercícios e atividades que promovam o engajamento.

Importante a indicação de links de pesquisa, slides, textos etc. O planejamento tanto das atividades que serão realizadas fora da sala de aula quanto aquelas realizadas no horário da aula devem ser feitas com certos cuidados, uma vez que os estudantes vêm, em geral, de uma formação mais passiva e esperam que o professor "dê" aula, ou seja, explique o conteúdo. Os dois conjuntos de atividades devem estar muito alinhados.

Uma vez encerrada a apresentação do tema Resolução de Problemas os professores demonstraram que já tinha certa familiarização com o tema, entretanto, avaliaram que eram necessários alguns cuidados nas escolhas das situações problema estabelecendo interfaces com situações cotidianas e que geram curiosidades e são desafiadoras e motivadoras.

Na sequência explanaremos sobre um jogo utilizado em sala de aula com alunos e, posteriormente, apresentados na formação de professores da OBMEP.

\section{O JOGO DE DARDO NO PROCESSO DE ENSINO/ APRENDIZAGEM DE MATEMÁTICA}

O segundo grupo, formado por dois professores, apresentou no terceiro encontro o papel do jogo para ensinar a calcular área do círculo e de suas partes.

Fundamentaram a apresentação evidenciando que, no Brasil, os Parâmetros Curriculares Nacionais de Matemática, em relação à inserção de jogos no ensino de matemática, pontuam que estes: "[...] constituem uma forma interessante de propor problemas, pois permitem que estes sejam apresentados de modo atrativo e favorecem a criatividade na elaboração de estratégias de resolução de problemas e busca de soluções. Propicia a simulação de situações-problema que exigem soluções vivas e imediatas, o que estimula o planejamento das ações [...]" (BRASIL, 1998, p. 46 ). 
Aportaram ainda, que Borin afirma que um:

Motivo para a introdução de jogos nas aulas de matemática é a possibilidade de diminuir bloqueios apresentados por muitos de nossos alunos que temem a Matemática e sentem-se incapacitados para aprendê-la. Dentro da situação de jogo, onde é impossível uma atitude passiva e a motivação é grande, notamos que, ao mesmo tempo em que estes alunos falam Matemática, apresentam também um melhor desempenho e atitudes mais positivas frente a seus processos de aprendizagem. (1996, p.9).

Uma vez embasados por autores que defendem a utilização dos jogos na sala de aula, antes de apresentarem aos professores da OBMEP no encontro presencial, eles tomaram a iniciativa de primeiramente, motivar seus os alunos a pesquisarem sobre o jogo de dardo e experimentar todo o processo até aprenderem a resolver os problemas matemáticos solicitados.

Entusiasmados com os resultados trouxeram para o encontro a sugestão que apresentamos a seguir:

\section{O JOGO DE DARDO NO PROCESSO DE ENSINOI APRENDIZAGEM DE MATEMÁTICA}

O jogo dos dardos é uma atividade desportiva que pode ser realizada em casa, nos bares e em torneios nacionais ou internacionais, e por que não na aula de matemática.

\section{Material necessário para jogar dardos}

Os dardos são um jogo que pode ser praticado de modo individual ou em equipas e ganha o competidor que chegar ao zero pontos primeiro. Trata-se de um jogo de inteligência muito simples e de fácil jogabilidade. Para o praticar é necessário reunir o material seguinte:

\section{Os dardos}

O peso e a forma dos dardos variam muito e isso deve-se ao material que é empregue na construção do corpo dos dardos. Pode ser feito em latão, níquel, titânio ou tungsténio. Geralmente, a maioria dos jogadores prefere os dados que são feitos em tungsténio, que é um metal mais pesado e denso, pois estes possibilitam uma maior precisão no lançamento dos dardos. As pontas que são utilizadas nos dardos também são mui- to importantes e estas podem ser feitas em aço, quando são utilizados alvos convencionais, ou em plástico quando os alvos são eletrônicos ou plásticos.

\section{O tabuleiro dos dardos}

O tabuleiro é o elemento mais importante num jogo de dardos, pois é nele que se desenrola toda a ação. Todos os tabuleiros de dardos são iguais e apresentam os números de 1 a 20 distribuídos de forma não sequencial ao redor do tabuleiro. $O$ centro do tabuleiro é chamado de mosca e esta é dívida em duas partes: a mosca interna (círculo central do tabuleiro) e a externa (círculo que envolve o círculo central).

Como jogar dardos

Depois de ter reunido todo o material necessário para jogar dardos, pode convidar os seus amigos para a realização de um jogo que é verdadeiramente viciante. Contudo, existem alguns aspectos que deve ter em atenção para a prática correta do jogo. São eles:

\section{A colocação do tabuleiro}

Para se tornar um bom jogador de dardos deve jogar de acordo com as medidas oficiais. Dessa forma, deve pendurar o tabuleiro para que a mosca esteja a 1,73 metros do chão, verificando se o tabuleiro fica bem preso à parede. Posteriormente, deve marcar a linha de onde os jogadores arremessarão os dardos. Essa linha, por norma, deve encontrar-se à distância de 2,37 metros do tabuleiro. Ao jogar sempre com as medidas oficiais conseguirá jogar dardos em qualquer tipo de ambiente e/ou competição.

\section{As regras do jogo}

Para que possa jogar dardos corretamente, é necessário que compreenda as regras deste jogo de precisão. Existem determinados locais que têm regras específicas, no entanto, das mais importantes destacam-se as seguintes:

É um desporto para ser jogado por dois jogadores ou duas equipas, apesar de existirem algumas variações;

Cada jogador de cada equipa deve arremessar o dardo contra o tabuleiro para determinar quem sai a jogar. Aquele que mais se aproximar da mosca, sai em primeiro lugar;

A cada jogador é permitido fazer 9 lançamentos de aquecimento antes do início de um jogo;

Cada jogador tem direito a lançar três dardos por cada ronda; 
Depois dos dardos serem lançados, contabilizam-se as pontuações e retiram-se os dardos do tabuleiro, antes de chegar a vez do adversário;

No momento do lançamento, todos os jogadores devem posicionar-se antes da linha de lançamento. Se o pé do jogador que está a lançar ultrapassar a linha de lançamento, esse lançamento não é válido;

No momento do lançamento, um jogador pode inclinar-se o máximo possível, desde que o seu pé não ultrapasse a linha de lançamento.

\section{A PONTUAÇÃO}

À medida que os dardos são lançados, os pontos conquistados pelo jogador são subtraídos ao seu total e ganha o jogador que atingir em primeiro lugar os zero pontos.

A contagem da pontuação dependerá sempre da modalidade que se pretenda jogar, pois pode jogarse para somar o máximo de pontos; ou ir subtraindo, de um determinado valor, os pontos acertados, até chegar a zero.

A subtração de pontos pode ser feita da seguinte forma:

Se um dardo acertar na parte negra ou amarela, o jogador faz o número de pontos que consta nessa secção;

Se um dardo acertar as secções exteriores verdes ou vermelhas, o jogador dobra os pontos que constam nessa secção;

Se um dardo acertar as secções interiores verdes ou vermelhas, o jogador triplica o número de pontos que constam nessa secção;

O maior número de pontos que um jogador pode fazer é 180, acertando os 3 dardos no triplo vinte;

Se um dardo atingir a mosca externa verde, o jogador acumula 25 pontos;

Se um dardo cair na mosca interna verde, o jogador faz 50 pontos;

Se um jogador lançar o dardo fora do arame externo ou do tabuleiro, ele não marca qualquer ponto naquele lançamento;

Vence o jogo, aquele que acertar o último dardo na área de pontuação a dobrar (secção exterior verde ou vermelha) para ficar com o resultado exatamente a zero pontos. Se, numa tentativa de lançamento, não forem contabilizados pontos suficientes para deixar o jogador com zero pontos, ou não for um duplo, o jogador não acumula ponto nenhum e tem de aguardar pela próxima ronda para jogar novamente.

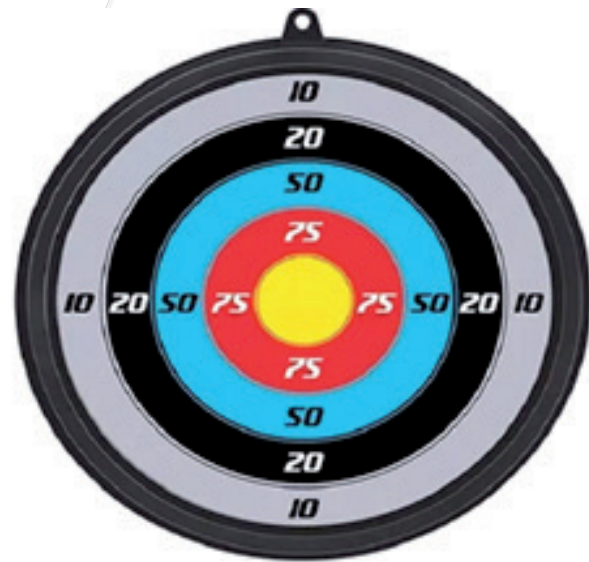

Figura 1: tabuleiro de dardo ${ }^{5}$ Figure 1: dart board

\section{dardos?}

O que explorar matematicamente no jogo de

Os professores em formação, com uso do celular, pesquisaram sobre o jogo na sala, encontraram várias curiosidades de campeonatos que suscitou diversas conversas sobre os modelos e tamanhos de tabuleiros e o grau de dificuldades dos níveis de campeonatos.

Os participantes foram motivados a praticarem arremessos de dardo ao tabuleiro, criaram competições e observando a dificuldade, dependendo da distância ao tabuleiro, o grau de dificuldade para obtenção de pontos.

O professor poderá solicitar aos alunos que vá ao tabuleiro e meça o $r=$ raio do círculo e o $\alpha=$ medida do ângulo central, para achar $\mathrm{A}=$ área dos arcos.

Em seguida, peça para que calculem a área total de cada círculo e verifique que a área é proporcional ao tamanho do raio e pode ser calculada pela expressão $\pi{ }^{*} r^{2}$, na qual $\pi$ equivale a 3,14 e r é a medida do raio do círculo.

Pode se pedir a área do setor circular com angulo central de $120^{\circ}$ e do segmento circular.

Feita a conferencia das atividades anteriores, tirado todas as dúvidas, o Professor poderá aproveitar para complementar sua aula, questionando:

${ }^{5}$ Disponível em: https://produto.mercadolivre.com.br/MLB1163746970-arco-e-flecha-com-luz-brinquedo-c-alvo-depontos-crianca- JM?quantity=1 
- Qual a distância do atirador até o alvo?

- Com que velocidade e o tempo gasto pelo dardo?

- Qual a maior probabilidade de pontuação? Justifique sua resposta.

- A que altura se encontrava o alvo ?

- Etc...

Pelo que verificamos, os professores adoraram a atividade e propuseram para seus alunos que participaram com muito entusiasmo e, principalmente, os professores afirmam que eles aprenderam os conceitos envolvidos nas situações-problema apresentadas.

Esse fato reverbera o pensamento de Kamii (1992) quando acena que com os jogos, "envolvem regras e interação social, e a possibilidade de fazer regras e tomar decisões juntos é essencial para o desenvolvimento da autonomia". (p.172) e, são tomadas de decisões que fazem com que o aluno deixa de ser passivo.

A metodologia ativa proposta foi a da Aprendizagem Baseada em Problemas - (Problem based Learning ou PBL) é uma metodologia completa, que organiza o currículo e que merece uma capacitação própria, mas isso não impede a utilização de problemas em salas de aula. É uma proposta para o desenvolvimento dos estudos sobre um tema específico. O objetivo de um problema é suscitar uma discussão produtiva entre os estudantes que permita o aprofundamento de seus conhecimentos sobre o tema gerador do problema. Um bom problema deve ser simples, objetivo e motivador.

No próximo item exporemos o que o terceiro grupo propiciou aos professores em formação, explorar conceitos matemáticos a partir de maquetes de casas confeccionadas por material de EVA.

\section{MODELAGEM MATEMÁTICA}

O Grupo 3, composto por quatro professores trabalhou com Modelagem Matemática. Inicialmente apresentaram o significado do tema com o texto a seguir.

Segundo Bassanezi (2004), "Modelagem Matemática é um processo dinâmico utilizado para a obtenção e validação de modelos matemáticos. É uma forma de abstração e generalização com a finalidade de previsão de tendências. A modelagem consiste, essencialmente, na arte de transformar situações da realidade em problemas matemáticos cujas soluções devem ser interpretadas na linguagem usual". (Bassanezi, 2004, p.24)

Bassanezi defende que a "Modelagem é eficiente a partir do momento que nos conscientizamos que estamos sempre trabalhando com aproximações da realidade, ou seja, que estarmos sempre elaborando sobre representações de um sistema ou parte dele". (2004:24)

A Modelagem Matemática, no ensino, deve ser vista apenas como uma estratégia de aprendizagem, onde o objetivo principal não é de se chegar a um modelo, mas seguir etapas aonde o conteúdo matemático vai sendo, no decorrer do processo, sistematizado e aplicado.

Para Bassanezi (2004), a Modelagem Matemática de uma situação problema real deve seguir uma sequência de etapas, de maneira simples visualizadas e discriminadas nas figuras.

Nesse sentido o grupo entendendo que Modelos Matemáticos e Situações Problemas envolvendo Modelagem Matemática possa motivar os alunos, apresentou uma maquete de uma casa de EVA como mostra a figura a seguir:

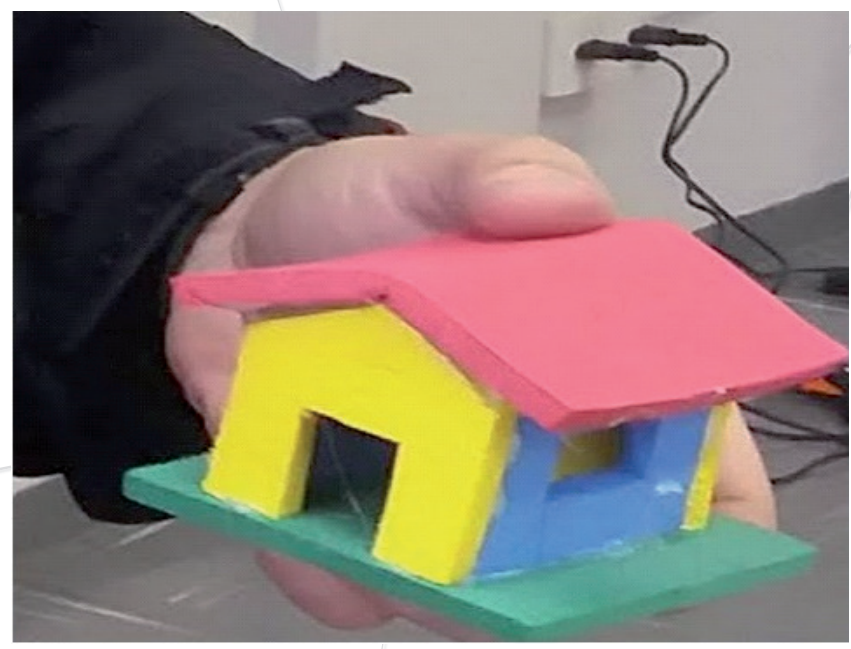

Figura 2: modelo de casa em EVA "Fonte: Própria( 2018)" Figure 2: Model made of EVA house "Source: Own (2018)"

A intenção era a de provocar, nos participantes, a curiosidade de como montar essa estrutura com material EVA ${ }^{6}$ e, principalmente, como explorar os conceitos matemáticos.

${ }^{6}$ EVA, em português, é a sigla de acetato-vinilo de etileno que deriva do inglês: Ethylene Vinyl Acetate, ou etileno acetato de vinila. 
Ressaltaram a importância de envolver os alunos em situações onde eles vivenciem empiricamente as atividades. O esquema a seguir delineia os processos de apreensão por parte dos alunos quando experimentam de forma pratica as atividades.

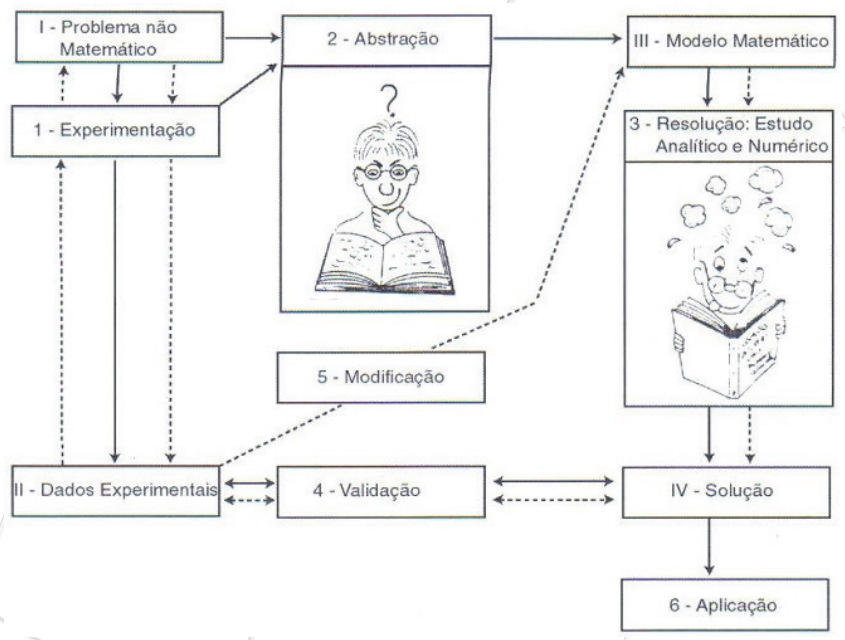

Figura 3: Esquema de Modelagem Matemática ${ }^{7}$ Figure 3: Mathematical Modeling Scheme

Junior (2011) vislumbra que na figura 2 as setas continuas indicam a primeira aproximação. A busca de um modelo matemático que melhor descreva o problema estudado torna o processo dinâmico, indicado pelas setas pontilhadas.

1. Experimentação: É uma atividade essencialmente laboratorial onde se processa a obtenção de dados;

2. Abstração: É o procedimento que deve levar à formulação dos Modelos Matemáticos;

3. Resolução: O modelo matemático é obtido quando se substitui a linguagem natural das hipóteses por uma linguagem matemática coerente - é como num dicionário, a linguagem matemática admite "sinônimos" que traduzem os diferentes graus de sofisticação da linguagem natural;

4. Validação: É o processo de aceitação ou não do modelo proposto. Nesta etapa, os modelos, juntamente com as hipóteses que lhes são atribuídas, devem ser testados em confronto com os dados empíricos, comparando suas soluções e previsões com os valores obtidos no sistema real. O grau de aproximação desejado destas previsões será o fator preponderante para validação;

${ }^{7}$ Figura 3.(BASSANEZI , 2004, p.27)
5. Modificação: Alguns fatores ligados ao problema original podem provocar a rejeição ou aceitação dos modelos. Quando os modelos são obtidos considerando simplificações e idealizações da realidade, suas soluções geralmente não conduzem às previsões corretas e definitivas, pois o aprofundamento da teoria implica na reformulação dos modelos. Nenhum modelo deve ser considerado definitivo, podendo sempre ser melhorado, poderíamos dizer que um bom modelo é aquele que propicia a formulação de novos modelos, sendo esta reformulação dos modelos uma das partes fundamentais do processo de modelagem.

Interação da modelagem Matemática perpassa por situação real para um modelo matemático

Essa interação, que permite representar um fenômeno através da linguagem matemática (modelo matemático), envolve uma série de procedimentos, que podem ser agrupados em três etapas, subdivididas em seis subetapas, a saber:

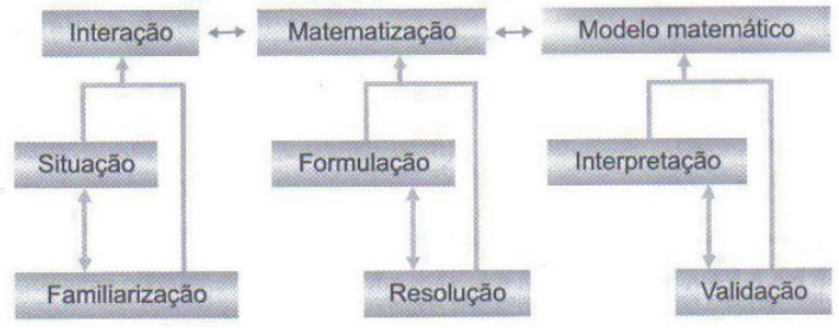

Figura 4: Interação do modelo matemático BIEMBENGUT e HEIN (2005, pág. 15)

Figure 4: Interaction of the mathematica model BIEMBENGUT e HEIN (2005, pág. 15)

\section{OFICINA: CONSTRUÇÃO DAS CASINHAS}

Uma vez explanado o conceito de Modelagem Matemática, foi proposto aos professores em formação que confeccionasse casinhas de EVA. Todos receberam materiais previamente cortados, cola quente, papelão, etc.

O grupo apresentador ressaltou a importância de compreender que a Modelagem Matemática deve auxiliar o ensino e não gerar um trabalho a mais, sendo assim o professor não deve interromper sua sequência de ensino para fazer à parte uma atividade de modelagem matemática. Esta deve estar em consonância com o programa estudado e não ser algo à parte.

Nessa proposta, manifestam-se os seguintes 
aspectos que entendemos ser fundamental no modelo matemático tais como, o reconhecimento da situação -problema, formulação do problema, analise e interpretação da solução e a validação.

A planta com material de papelão: realizando outras aplicações.
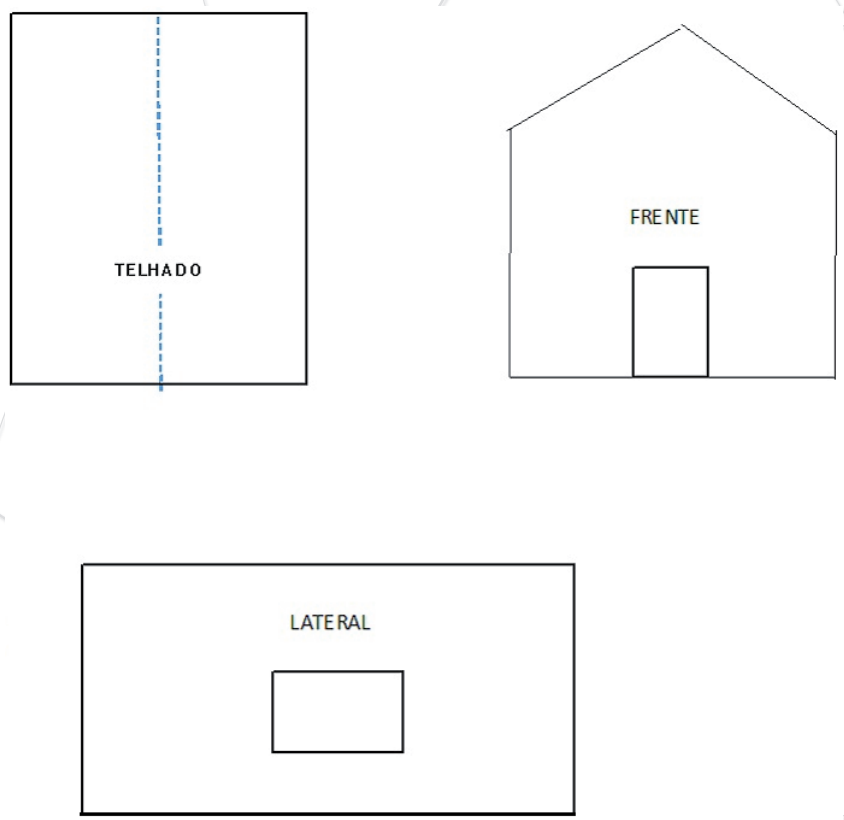

Figura 5: planta da casa. Próprio (2018) Figure 5: house plan 1"Source: Own (2018)"

\section{ALGUMAS DISCUSSÕES QUE FORAM PROPOSTAS NA OFICINA}

Após os professores confeccionarem as casinhas foi proposto algumas reflexões sobre quais tipos de questionamentos podemos levantar durante a oficina?

Consensuou-se que existem inúmeras maneiras que se poderia adotar para construção de uma casa, entretanto, em todas elas se faz necessário: mão de obra, terreno, material (cimento, tijolo, brita), a planta da casa, entre outros.

Para projetá-la não basta decidir sobre o tamanho, fachada, formato, mas é preciso também procurar meios que garantam o conforto desse ambiente, por meio do posicionamento dos cômodos e aberturas (janelas e portas), temperatura, luminosidade e ventilação. Nesse contexto, o projetista terá que observar o posicionamento do sol no decorrer do ano, o clima da região, assim como as condições do terreno.

Questionaram em seguida, quais conceitos Matemáticos poderiam ser desvelados?

Os participantes contribuíram de forma entusiasmada afirmando que era possível transitar por todos os blocos de conteúdos como Tratamento da Informação, Números e Operações, Grandezas e Medidas, Geometria e Álgebra.

$\mathrm{Na}$ atividade solicitada, determinou-se que era possível trabalhar os conceitos e propriedades dos polígonos, área das paredes, área do telhado, área dentro da casa, ângulos, etc.

A atividade que está conectada com a vida real pode ser trazida para a sala de aula e matematizada de tal forma que possa ser discutido diversos conceitos matemáticos e, principalmente, envolver os alunos nas atividades.

A metodologia ativa presente na apresentação foi a da aula expositiva e interativa. Num primeiro momento o grupo apresentou com auxílio de Power Point os conceitos de Modelagem Matemática, fazendo uso de questionamentos para envolver os pares de formação e, posteriormente, levou-os a confeccionarem as casinhas e explorou, novamente, com perguntas e respostas os conceitos matemáticos que poderiam ser aventados nessa atividade.

Os impactos da formação na postura e na voz dos professores participantes

Havia 19 professores contratados para ensinar matemática para alunos da rede pública que gostariam de realizar as provas das Olímpiadas Brasileira de Matemática das Escolas Públicas - OBMEP. Desses, 18 eram assíduos e participativos nos encontros de formação.

Nos encontros, iniciávamos passando algumas orientações importantes relacionadas a parte administrativa. Explicitamos algumas:

1. Entrega de materiais (apostilas, cronogramas, etc) para cada professor para que sejam entregues aos seus alunos.

2. Recolhíamos as listas de chamadas e provas corrigidas que os alunos realizavam para arquivamento;

3. Reafirmávamos sobre o número de alunos que deveriam frequentar as turmas para que 
pudéssemos manter a sala sendo, o mínimo 20 alunos e máximo 40 alunos;

4. Os professores receberão um termo de ciência que a turma tem mais de 20 alunos e esses alunos a mais a OBMEP não tem responsabilidade de material.

5. Avaliações eram obrigatórias e contavam com 2 questões dissertativas tem que ser resolvidas em aula. Podem ser resolvidas em duplas, mas cada aluno tem que escrever a sua solução e entregar individualmente para o professor. O professor corrigi - de acordo com os critérios de correção determinado e atribui uma nota para cada aluno. Após a correção o professor deve comentar com a turma as soluções ou erros frequentes.

6. Tarefa (Simulado) - solicitávamos comentários de como havia ocorrido.

7. 3 questões para tarefa de casa, distribuir aos alunos no $1^{\circ}$ encontro do ciclo, essas três questões. Os alunos devem levar os exercícios para casa e depois de um tempo devolver para o professor que deve corrigir as provas. Após a correção os professores devem discutir com os alunos a solução.

8. Orientações sobre o preenchimento dos Diários contendo o detalhamento das atividades, quando não há avaliação colocar nesse item não houve. Atenção aos prazos para o preenchimento dos diários, etc.

Essas eram algumas das orientações necessárias para o registro dos encontros entre professores e alunos. Na sequência, solicitávamos aos professores, que fizessem um breve relato de como teria ocorrido os encontros com os alunos, que apresentassem possíveis dificuldades enfrentadas, sugestões de melhorias, se era pertinente os conteúdos conceituais disponibilizados pela OBMEP e trabalhado com relação ao nível dos alunos, etc.

Como afirmamos anteriormente, toda a formação tem que ser repensada à medida que está sendo desenvolvida considerando os objetivos que queremos atingir e as expectativas de todos os envolvidos, ao ouvir os professores refletíamos sobre o que seria necessário como intervenção para auxilia-los em suas pertinentes queixas.

Uma das ações era a elaboração de um relatório feito por nós e enviado para a coordenação geral no Rio de Janeiro que analisava e nos dava respaldo para apoiar os professores.

Os depoimentos dos professores eram alentadores, no sentido que alguns deles comentarem que ao iniciar as formações, não acreditavam que seria possível mudanças em suas posturas acadêmicas.

Muitos deles estavam encantados com as transformações que estavam ocorrendo em suas aulas regulares e nas turmas da OBMEP.

Tivemos um depoimento de um professor que afirmou e confirmamos com a direção da escola onde ele leciona, o fato que relatado pelo professor:

"foi oferecida aula de voleibol pelo professor de Educação Física no mesmo horário em que ofertei as aulas de Matemática com vistas as Olimpíadas de Matemática. O professor de Educação Física teve que alterar o horário por que a adesão foi quase maciça em Matemática. Nunca imaginei isso!"

Outros professores mencionaram:

"trabalhar com ênfase na Resolução de Problemas e Modelagem Matemática, traz significado aos conteúdos matemáticos e os alunos sentem-se importantes quando analisam, tomam decisão e argumentam possibilidades de resolução".

"Nunca imaginei que seria possível eu mudar de estratégia e fazer com que meus alunos briguem por aulas de Matemática. Trabalhei com eles com casinha de EVA e foi um sucesso. Todos ficaram motivados e felizes".

"Eu mudei muito, como professor me sentia tímido, fica na minha nas formações. Hoje, me sinto à vontade de participar, de propor sugestões e/ ou encaminhamentos, sem medo de errar ou de não ser aceita minha sugestão. Cada dia aprendo mais com meus alunos. Dá traballho pesquisar e preparar atividades, mas, no final, é bem melhor lecionar dessa forma. Os alunos aprendem de fato". 
Poderíamos ficar aqui explicitando diversas falas dos professores que participaram das formações do Projeto OBMEP NA ESCOLA (ONE), entretanto, o que tornou significativo em nosso trabalho foi perceber que as discussões e reflexões não ficaram restritos aos encontros de formação.

Temos diversas fotos e depoimentos de coordenadores e diretores das escolas na qual esses professores atuam, tecendo muitos elogios sobre a postura didática em sala de aula.

Observamos que vários alunos desses professores em 2017 e 2018 tiveram ótimos rendimentos nas olimpíadas conquistando medalhas de bronze, prata ou ouro. Alguns deles não conseguiram medalhas, mas, pelo bom aproveitamento tiveram menção honrosa e, desses, alguns foram convidados a participar de curso de iniciação cientifica da OBMEP - PIC.

Um desses professores, José Ademir Machado Junior, foi entrevistado, pelo Jornal da Tribuna - San- tos, por fazer a diferença na escola, preparando alunos para concorrerem as Olimpíadas de Matemática da OBMEP numa escola da periferia de Santos e, a matéria foi publicada na revista Atrevista que é veiculada juntamente com o jornal A Tribuna.

Acreditamos que uma parceria entre Órgãos como a OBMEP, formadores e professores sinalizam trajetórias instigantes para levar os alunos a aprenderem Matemática.

O grupo de professores com que trabalhei sempre se mostrou com vontade de fazer algo que pudessem para melhorar a Educação, particularmente, o ensino da Matemática nas escolas públicas.

A vivência empírica permitiu que esses professores, experimentando a resolução de situações -problema como alunos, levou-os a compreenderem o quanto é significativo e essencial que promovam a seus alunos essas vivências para aprenderem Matemática em sala de aula. 


\section{REFERÊNCIAS}

BARBOSA, Jonei Cerqueira. Discussões sobre Modelagem Matemática. Disponível em: www. somatematica.com.br/artigos/a8. Acesso em: 21 jul. 2006.

BASSANEZI, Rodney Carlos. Ensino-aprendizagem com Modelagem Matemática. São Paulo: Contexto, 2004.

BRASIL. Secretaria de educação fundamental. Parâmetros Curriculares Nacionais: Matemática. Brasília: MEC/SEF, 1998.

BIEMBENGUT, Maria Sallet; HEIN, Nelson. Modelagem Matemática no Ensino. São Paulo: Editora Contexto, 2005.

BORIN, J. Jogos e resolução de problemas: uma estratégia para as aulas de matemática. 3. ed. São Paulo: IME/USP, 1996.

CARNEIRO, Carlos Henrique; LIMA, José Fábio de Araújo; SILVA, Sidney Soares. Desvendando alguns mistérios de questões da OBMEP. XII Encontro Nacional de Educação Matemática. São Paulo, 2016.
CERQUEIRA, Dermeval Santos. Implementação de inovações curriculares no Ensino Médio e formação continuada de professores: as lições de uma experiência. Mestrado em Educação Matemática, PUCSP, São Paulo, 2003. Um estudo comparativo entre Brasil e Chile sobre Educação Matemática e sua influência nos currículos de Matemática desses países. Tese de Doutorado. PUCSP, São Paulo, 2012.

JUNIOR, Cícero Pinheiro dos Santos. Modelagem matemática: uma ferramenta importante para aprendizagem do ensino da Matemática no mundo das tecnologias. CIAEM, Recife, 2011.

KAMII, Constance; DECLARK, Geórgia. Reinventando a aritmética: implicações da teoria de Piaget. São Paulo: Papirus, 1992. Disponível em: <https:// jogolaxia.com/artigos/como-jogar-dardos>. Acesso em: 23 de maio de 2018, as $15 \mathrm{~h} 57 \mathrm{~min}$. Novo acesso em: 14 de abril de 2019, as 19h12 min.

LIBANEO, José Carlos. Didática. São Paulo: CORTEZ, 1994. (Coleção Magistério $2^{\circ}$ grau. Série Formação do Professor). 